\title{
PERFORMANCE OF ALKALINE SOLUTIONS ON GRADES OF GEOPOLYMER CONCRETE
}

\author{
Shankar H. Sanni ${ }^{1}$, R. B. Khadiranaikar ${ }^{2}$ \\ ${ }^{1}$ Assistant Professor, ${ }^{2}$ Professor, Department of Civil Engineering, Basaveshwar Engineering College, Bagalkot- \\ 587102, India,shsanni@gmail.com
}

\begin{abstract}
Geopolymer is a class of aluminosilicate binding materials synthesized by thermal activation of solid aluminosilicate base materials such as fly ash, metakaolin, GGBS etc., with an alkali metal hydroxide and silicate solution. The geopolymer was activated with sodium hydroxide, sodium silicate and heat. This paper presents the experimental investigation done on the variation of alkaline solution on mechanical properties of geopolymer concrete. The grades chosen for the investigation were $M-30, M-40, M-50$ and $M$ 60, the mixes were designed for 8 molarity. The alkaline solution used for present study was the combination of sodium silicate and sodium hydroxide solution with the varying ratio of 2, 2.50, 3 and 3.50. The test specimens were 150x150x150 mm cubes and 100x200 $\mathrm{mm}$ cylinders heat-cured at $60^{\circ} \mathrm{C}$ in an oven. The results revealed that the workable flow of geopolymer concrete was in the range of 85 to 145 and was dependent on the ratio by mass of sodium silicate and sodium hydroxide solution. The freshly prepared geopolymer mixes were cohesive and their workability increased with the increase in the ratio of alkaline solution.
\end{abstract}

The strength of geopolymer concrete can be improved by decreasing the water/binding and aggregate/binding ratios. The curing period improves the polymerization process resulting in higher compressive strength. The geopolymer concrete do not have any Portland cement, they can be considered as less energy interactive. It utilizes the industrial wastes such as fly ash for producing the binding system in concrete.

The obtained compressive strength and split tensile strength were in the range of $20.64-60 \mathrm{~N} / \mathrm{mm}^{2}$ and $3-4.9 \mathrm{~N} / \mathrm{mm}^{2}$. The optimum dosage for alkaline solution can be considered as 2.5, because for this ratio the GPC specimens of any grade produced maximum strength in compression and tension.

Keywords: geopolymer concrete, fly ash, molarity, sodium silicate, sodium hydroxide

\section{INTRODUCTION}

The global cement industry contributes around 1.35 billion tons of the green house gas emissions annually, or about $7 \%$ of the total man-made greenhouse gas emissions to the earth's atmosphere [1]. Due to the production of Portland cement, it is estimated that by the year 2020, the $\mathrm{CO}_{2}$ emissions will rise by about $50 \%$ from the current levels. Therefore, to preserve the global environment from the impact of cement production, it is now believed that new binders are indispensable to replace PC [2]. In this regard, the geopolymer concrete (GC) is one of the revolutionary developments related to novel materials resulting in low-cost and environmentally friendly material as alternative to PC [3].

The geopolymer technology was first introduced by Davidovits in 1978. His work considerably shows that the adoption of the geopolymer technology could reduce the $\mathrm{CO}_{2}$ emission caused due to cement industries. Davidovits proposed that an alkaline liquid could be used to react with aluminosilicate in a source material of geological origin or in by-product materials such as fly ash to make a binder [4].
Geopolymer is synthesized by mixing aluminosilicate-reactive material with strong alkaline solutions, such as sodium hydroxide $(\mathrm{NaOH})$, potassium hydroxide $(\mathrm{KOH})$, sodium silicate or potassium silicate. The mixture can be cured at room temperature or temperature cured [5]. Fly ash is the most common source material for making geopolymers. Normally, good high-strength geopolymers can be made from class F fly ash [6]. Alkaline activating solution is important for dissolving of $\mathrm{Si}$ and $\mathrm{Al}$ atoms to form geopolymer precursors and finally alumino-silicate material. The most commonly used alkaline activators are $\mathrm{NaOH}$ and $\mathrm{KOH}$ [7-11].

\section{EXPERIMENTAL INVESTIGATIONS}

\subsection{Materials}

The following materials have been used in the experimental study [14]

a) Fly Ash (Class F) collected form Raichur Thermal power plant having specific gravity 2.00 . 
b) Fine aggregate: Sand confirming to Zone -III of IS:383-1970 [18] having specific gravity 2.51 and fineness modulus of 2.70 .

c) Coarse aggregate: Crushed granite metal confirming to IS:383-1970 [18] having specific gravity 2.70 and fineness modulus of 5.85 .

d) Water : Clean Potable water for mixing

e) Alkaline liquids: Specific gravity of

i) Sodium Hydroxide $(\mathrm{NaOH})=1.16$

ii) Sodium Silicate $\left(\mathrm{Na}_{2} \mathrm{SiO}_{3}\right)=1.57$

Tests were conducted on specimen of standard size as per IS: 516-1959 and IS: 5186-1999 [19-20]. Details of tests conducted and specimens used are given in Table 1.

\subsection{Mix Design of Geopolymer Concrete}

In the design of geopolymer concrete mix, coarse and fine aggregates together were taken as $77 \%$ of entire mixture by mass. This value is similar to that used in OPC concrete in which it will be in the range of 75 to $80 \%$ of the entire mixture by mass. Fine aggregate was taken as $30 \%$ of the total aggregates. The density of geopolymer concrete is taken similar to that of OPC as $2400 \mathrm{~kg} / \mathrm{m}^{3}$ [12]. The details of mix design and its proportions for different grades of GPC are given in Table 2 .

\subsection{Alkaline Solution}

In geopolymerization, alkaline solution plays an important role. The most common alkaline solution used in geopolymerization is a combination of sodium hydroxide $(\mathrm{NaOH})$ or potassium hydroxide $(\mathrm{KOH})$ and sodium silicate $\left(\mathrm{Na}_{2} \mathrm{SiO}_{3}\right)$ or potassium silicate $\left(\mathrm{K}_{2} \mathrm{SiO}_{3}\right)$. In this study, a combination of sodium hydroxide and sodium silicate was choosen as the alkaline liquid. Sodium based solutions were choosen because they are cheaper than Potassium based solutions. Generally sodium hydroxide and sodium silicate are readily available in market in the form of pellets and gel (liquid).

\subsection{Preparation, Casting and Curing of Geopolymer}

\section{Concrete}

The alkaline activator solution used in GPC mixes was a combination of sodium hydroxide solution, sodium hydroxide pellets and distilled water. The role of AAS is to dissolve the reactive portion of source materials $\mathrm{Si}$ and $\mathrm{Al}$ present in fly ash and provide a high alkaline liquid medium for condensation polymerization reaction. To prepare sodium hydroxide solution of 8 molarity $(8 \mathrm{M}), 320 \mathrm{~g}$ of sodium hydroxide flakes was dissolved in water. The mass of $\mathrm{NaOH}$ solids in a solution will vary depending on the concentration of the solution expressed in terms of molar, M. The pellets of $\mathrm{NaOH}$ are dissolved in one liter of water for the required concentration. When sodium hydroxide and sodium silicate solutions mixed together polymerization will take place liberating large amount of heat, which indicates that the alkaline liquid must be used after 24 hours as binding agent.

GPC can be manufactured by adopting the conventional techniques used in the manufacture of Portland cement concrete. In the laboratory, the fly ash and the aggregates were first mixed together dry on pan for about three minutes. The liquid component of the mixture is then added to the dry materials and the mixing continued usually for another four minutes [Fig. 1 and 2].

The addition of sodium silicate is to enhance the process of geopolymerization [12]. For the present study, concentration of $\mathrm{NaOH}$ solution is taken as $8 \mathrm{M}$ with varying ratio of $\mathrm{Na}_{2} \mathrm{SiO}_{3} / \mathrm{NaOH}$ as 2, 2.5, 3 and 3.5 for all the grades of GPC mixes.

The workability of the fresh concrete was measured by means of conventional slump test [Fig. 4]. In order to improve the workability, superplasticizer Conplast SP-430 with a dosage of $1.5 \%$ by mass of the fly ash was added to the mixture. Extra water (other than the water used for the preparation of alkaline solutions) and dosage of super plasticizer was added to the mix according to the mix design details. The fly ash and alkaline activator were mixed together in the mixer until homogeneous pate was obtained. This mixing process can be handled within 5 minutes for each mixture with different ratios of alkaline solution. Heat curing of GPC is generally recommended, both curing time and curing temperature influence the compressive strength of GPC [12-14]. After casting the specimens, they were kept in rest period for two days and then they were demoulded. The demoulded specimens were kept at $60^{\circ} \mathrm{C}$ for 24 hours in an oven as shown in Fig. 3. The demoulded procedure is similar to that of routine conventional concrete [Fig. 6].

\section{RESULTS AND DISCUSSIONS}

\subsection{Workability}

Fresh GPC mixes were found to be highly viscous and cohesive with medium to high slump. The workability of the geopolymer concrete decreases with increase in the grade of the concrete as presented in Fig. 5, this is because of the decrease in the ratio of water to geopolymer solids. The ratio of alkaline solution increases the slump value for any grade of GPC, this is due to the fact that there will be more amount of sodium silicate solution and the water present in the fly ash will be released into the mixture during the mixing. An increase in sodium silicate concentration thus reduces the flow of GPC. Hence we can say that as the grade of the concrete increases, the mix becomes stiffer decreasing the workability, which result in strength reduction. 


\subsection{Effect of Ratio of Sodium Hydroxide to Sodium}

\section{Silicate Solution}

The effect of ratio of sodium hydroxide to sodium silicate solution by mass on the compressive strength of concrete can be seen by comparing the results. For these grades the concentration of sodium silicate solution (in terms of molarity), the water content, the fly ash content and the condition of curing were kept constant. The ratio was varied from 2 to 3.5 , in the increment of 0.5 . the average maximum strength was obtained when the ratio was 2.5 .

\subsection{Compressive Strength}

The compressive strength is one of the most noteworthy properties of hardened concrete and is considered as the characteristic material value for the classification of concrete. The compressive strength of the GPC specimens synthesized at four different alkaline ratios as shown in Fig. 7-10. The chemical reaction of the geopolymer gel is due to substantially fast polymerization process, the compressive strength do not vary with the age of concrete. This observation is in contrast to the well-known behavior of OPC concrete, which undergoes hydration process and hence gains strength over the time. The cube specimens of the GPC mixes, when tested under compression, generally failed in the 'pyramidal frustum' form, similar to the regular Portland cement concrete cubes.

It is clear from the test results that maximum strength was observed for the alkaline ratio of 2.5 , this variation was true for any grade of concrete. The trend of results was in par with the observations made by Hardjito et al [11]. The strength increased with the increase of $\mathrm{NaOH}$ concentration mainly through the leaching out of silica and alumina [18].

\subsection{Split Tensile Strength}

The split tensile strength of geopolymer concrete is only a fraction of compressive strength, as in case of Ordinary Portland cement concrete. The variation of results are presented in Fig. 11-14. From those graphs it is clear that as the alkaline ratio increases for any grade the split tensile strength increases up to ratio of 2.5 , then suddenly the results goes on decreasing for alkaline ratios of 3 and 3.5 , hence we can conclude that the split tensile strength results are in match with cube compressive strength.

\section{CONCLUSIONS}

Based on the experimental investigations done the following conclusions can be drawn:

- For any grade of GPC, as ratio of alkaline solution increases, the workability of mix goes on increasing.

- The study showed that the strength of geopolymer concrete can be improved by decreasing the water/binding and aggregate/binding ratios. It was observed that water influences the geopolymerization process and the hardening of concrete. Inclusion of increased binder content enhances the geoplymerization and affects the final strength.

- The optimum dosage for alkaline solution, which is used a geopolymer binder can be considered as 2.5 , because for this ratio, the GPC specimens of any grade produced maximum strength results with compression and tension.

- The fly ash can be used to produce geopolymeric binder phase which can bind the aggregate systems consisting of sand and coarse aggregate to form geopolymer concrete (GPC). Therefore these concretes can be considered as eco-friendly materials.

\section{REFERENCES}

[1] Hardjito, D., Wallah, S.E., Sumajouw, DMJ and Rangan, B.V., 'Factors influencing the compressive strength of fly ash based geopolymer concrete', Civil Engineering Dimension SIPIL, 6(2), 2004, pp. 88-93.

[2] Fareed Ahmed, M., Fadhil Nuruddin, M and Nasir Shafiq, 'Compressive strength and workability characteristics of low calcium fly ash based self compacting geopolymer concrete', World Academy of Science, Engineering and Technology, 74, 2011, pp. 814.

[3] Davidovits, J., 'Geopolymers: inorganic polymeric new materials', Journal of Thermal Analysis, 37(8), 1991, pp. 1633-1656.

[4] Rangan, B. V., 'Studies on low-calcium fly ash based Geopolymer concrete', Indian Concrete Institute, 2006, pp. 9-17.

[5] Davidovits, J., 'Geopolymer chemistry and application, Institute Geopolymer, France, 2008, pp. 585.

[6] M. Schmucker, $M$ and MacKenzine, KJD, 'Microstructure of sodium polysialate siloxogeopolymer', Ceramic International, 31, 2004, pp. 433-437.

[7] Fenandez-Jimenez, A and Palomo, A., 'Characteristics of fly ashes, Potential reactivity as alkaline cements', Fuel, 2003, pp. 2259-2265.

[8] Davidovits, J., 'Chemistry of Geopolymeric systems Terminology', 99 International Conference, SaintQuentin, France, 30 June-2 July 1999.

[9] Fernandez-Jimenez, A., Palomo, J. and Puertas, F., Alkali activated slag mortars, mechanical strength behavior, Cement and Concrete Research, 29, 1999, pp. 1323-1329.

[10] Hua Xu, van Deventer, J.S.J., 'The Geopolymerisation of Alumino-Silicate Minerals', International Journal of Mineral Processing, 59(3), 2000, pp. 247-266.

[11] Hardjito, D., Wallah, S.E., Sumajouw, DMJ and Rangan, B.V., 'On the development of fly ash based geopolymer concrete', ACI Materials Journal, 101(52), 2004, pp. 467-472. 
[12] Rangan, B. V., 'Mix design and production of fly ash based geopolymer concrete', The Indian Concrete Journal, 82(5), 2008, pp. 7-14.

[13] Kiatsuda Somna, Chai Jaturapitakkul, Puangrat Kajitvichyanukul and Prinya Chindaprasirt, 'NaOHactivated ground fly ash geopolymer cured at ambient temperature', Fuel,(90), 2011, pp. 2118-2124.

[14] Mahaltesh, S., 'Experimental study on ratio of alkaline liquids on geopolymer concrete', M.Tech Project Report, 2011, Basaveshwar Engineering College, Bagalkot.

[15] Shetty, M. S., 'Concrete Technology', Fifth Revised Edition, S. Chand and Company Ltd., New Delhi, 2002.
[16] IS: 2386 (Part-IV)-1963, Methods of test for aggregates for concrete-mechanical properties, Bureau of Indian standards, New Delhi.

[17] IS: 456-2000, Code of practice for plain and reinforced concrete, Bureau of Indian standards, New Delhi

[18] IS: 383-1970, Specification for coarse and fine aggregates from natural sources for concrete, Bureau of Indian standards, New Delhi

[19] IS: 516-1959, Methods of test for strength of concrete, Bureau of Indian standards, New Delhi

[20] IS:5816-1999, Methods of test for splitting tensile strength of concrete cylinders, Bureau of Indian standards, New Delhi

Table 1: Details of specimen used and tests conducted

\begin{tabular}{|l|l|c|}
\hline \multicolumn{1}{|c|}{ Type of test conducted } & \multicolumn{1}{|c|}{ Size of specimen } & No. of specimen cast for different grades \\
\hline Compressive strength & $150 \times 150 \times 150 \mathrm{~mm}$ & 5 \\
\hline Split tensile strength & $100 \times 200 \mathrm{~mm}$ & 5 \\
\hline
\end{tabular}

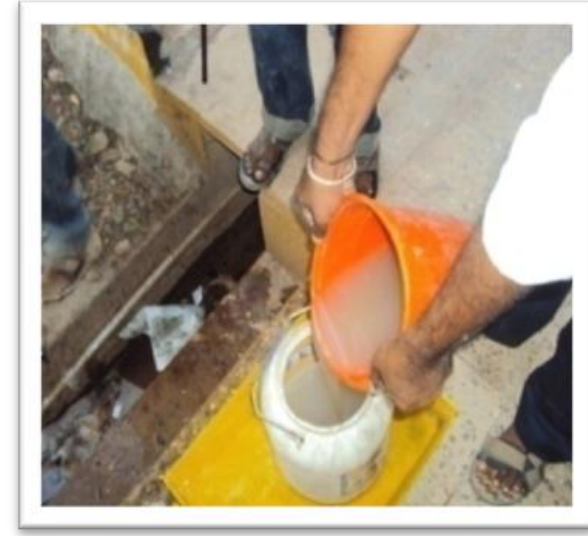

Fig. 1: Mixing of alkaline solution

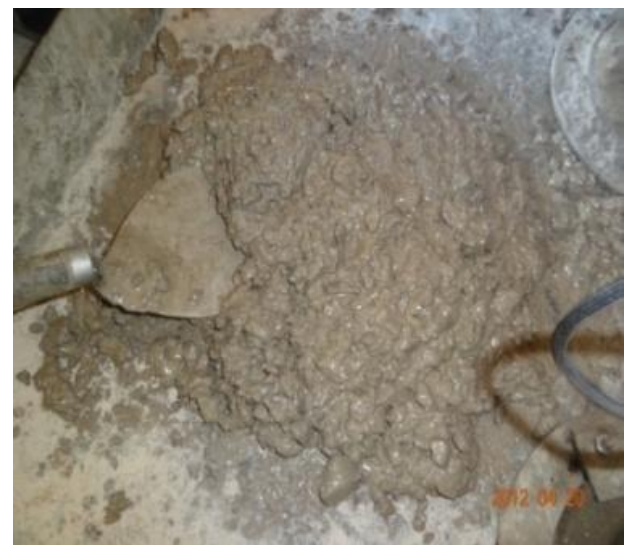

Fig. 2: Mixing of GPC

Table 2: Geopolymer concrete mix design details

\begin{tabular}{|c|c|c|c|c|c|c|c|c|c|c|}
\hline & & & & & Mate & als $(\mathrm{kg} / \mathrm{m}$ & & & & \\
\hline Grade & Coarse & aggregat & $\mathrm{s}(\mathrm{mm})$ & Fine & Fly & $\mathrm{Na}_{2} \mathrm{SiO}_{3} /$ & $\mathrm{NaOH}$ & $\mathrm{Na}_{2} \mathrm{SiO}_{3}$ & Super & Extra \\
\hline & 20 & 14 & 7 & sand & ash & $\mathrm{NaOH}$ & solution & solution & Plasticizer & water \\
\hline M-30 & & & & & & & 57.10 & 114.21 & 5.70 & 38.06 \\
\hline M-40 & 2077 27 & 36060 & 64680 & 55440 & 38060 & 200 & 52.57 & 105.14 & 5.91 & 39.42 \\
\hline M-50 & 211.20 & 509.00 & 040.00 & 534.40 & 500.09 & 2.00 & 47.70 & 95.41 & 6.13 & 40.88 \\
\hline M-60 & & & & & & & 42.46 & 84.92 & 6.37 & 42.46 \\
\hline M-30 & & & & & & & 48.95 & 122.36 & 5.70 & 38.06 \\
\hline M-40 & 2077 27 & 36060 & 64680 & 55440 & 38060 & 250 & 45.06 & 112.65 & 5.91 & 39.42 \\
\hline M-50 & 211.20 & 509.00 & 040.00 & 534.40 & 500.09 & 2.50 & 40.89 & 102.22 & 6.13 & 40.88 \\
\hline M-60 & & & & & & & 36.40 & 91.00 & 6.37 & 42.46 \\
\hline M-30 & & & & & & & 42.83 & 128.48 & 5.70 & 38.06 \\
\hline M-40 & 2077 27 & 36060 & 64680 & 55440 & 38060 & 300 & 39.43 & 118.29 & 5.91 & 39.42 \\
\hline M-50 & 211.20 & 509.00 & 040.00 & 534.40 & 500.09 & 3.00 & 35.78 & 107.33 & 6.13 & 40.88 \\
\hline M-60 & & & & & & & 31.85 & 95.54 & 6.37 & 42.46 \\
\hline M-30 & & & & & & & 38.07 & 133.24 & 5.70 & 38.06 \\
\hline M-40 & & 36060 & 64680 & 55440 & 28060 & 250 & 35.05 & 122.67 & 5.91 & 39.42 \\
\hline M-50 & 271.20 & 309.00 & 040.80 & 554.40 & 380.09 & 3.50 & 31.80 & 111.31 & 6.13 & 40.88 \\
\hline M-60 & & & & & & & 28.31 & 99.08 & 6.37 & 42.46 \\
\hline
\end{tabular}




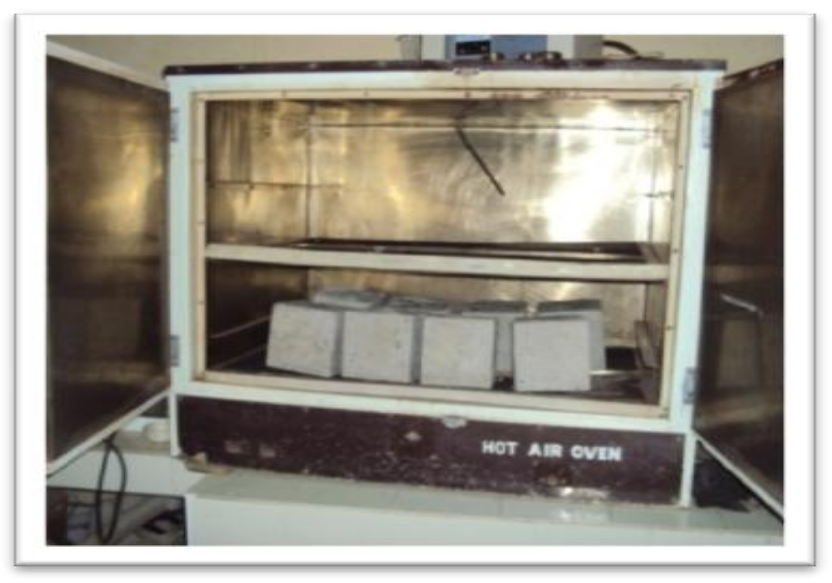

Fig. 3: Curing of GPC specimens

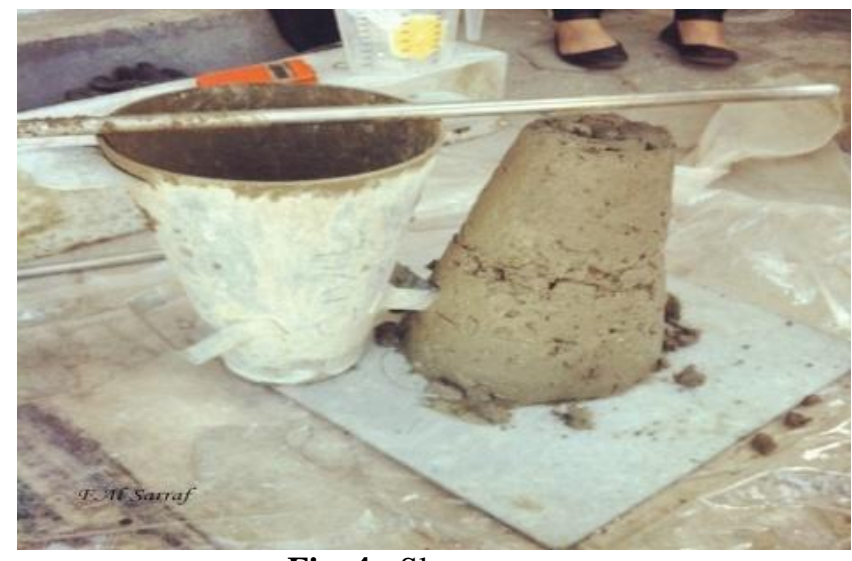

Fig. 4: Slump cone test

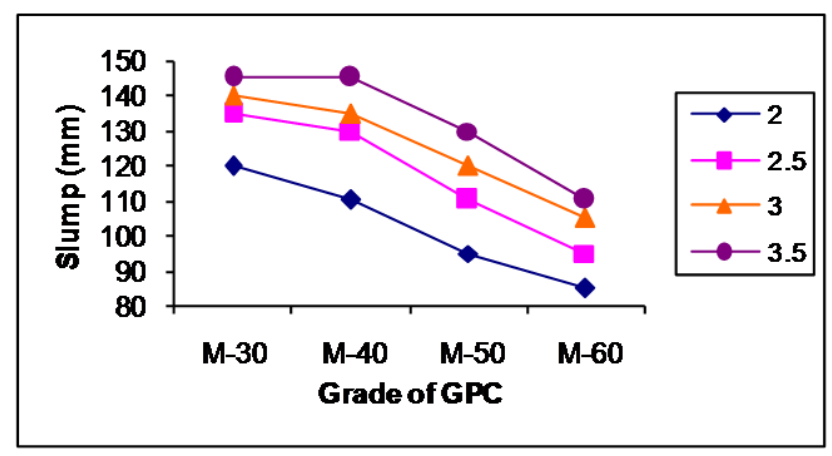

Fig. 5 Workability of GPC mixes

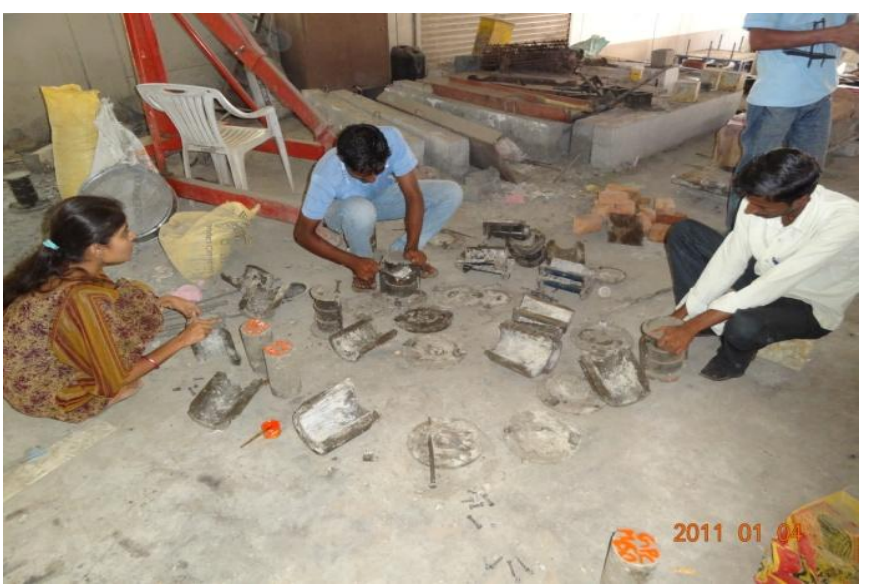

Fig. 6 Demoulding of GPC specimens

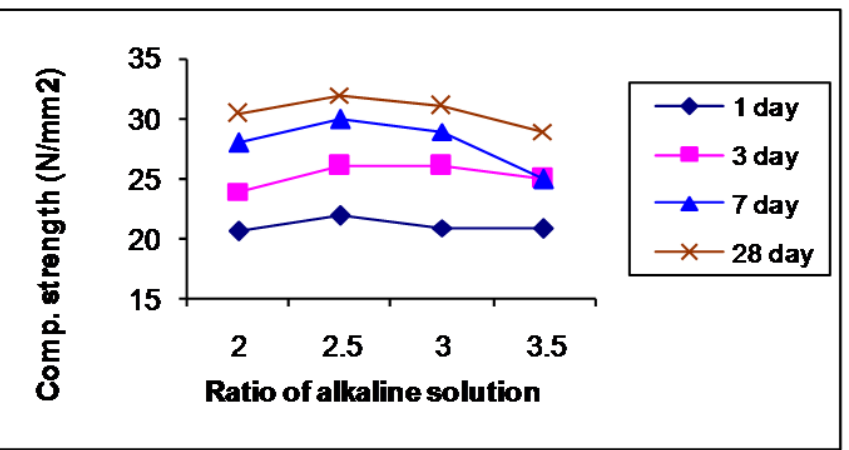

Fig. 7 Comp. strength Vs Alkaline ratio (M-30)

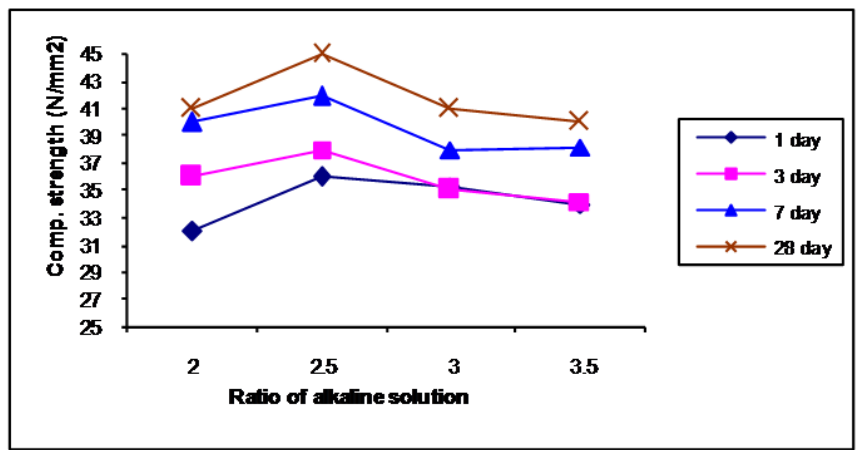

Fig. 8 Comp. strength Vs Alkaline ratio (M-40) 


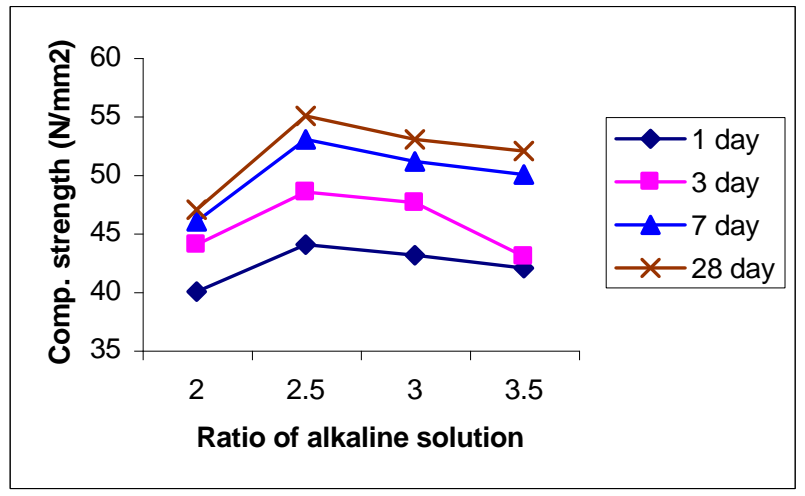

Fig. 7 Comp. strength Vs Alkaline ratio (M-30)

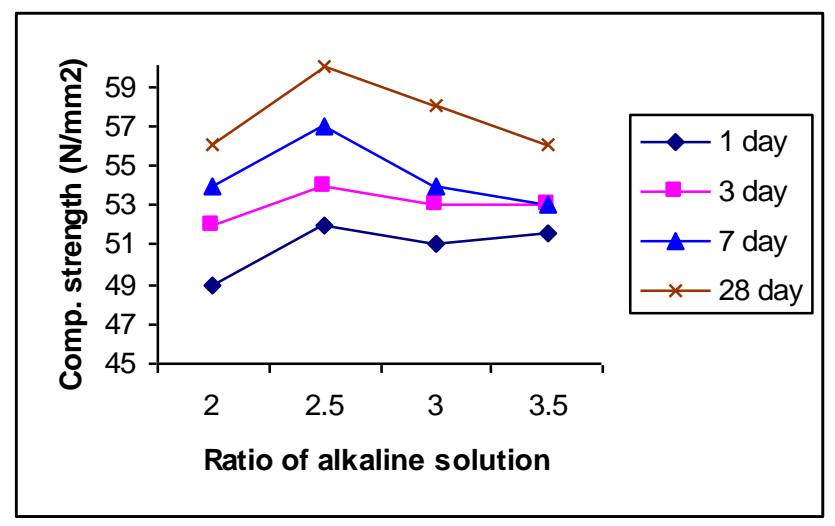

Fig. 10 Compressive strength Vs Alkaline ratio (M-60)

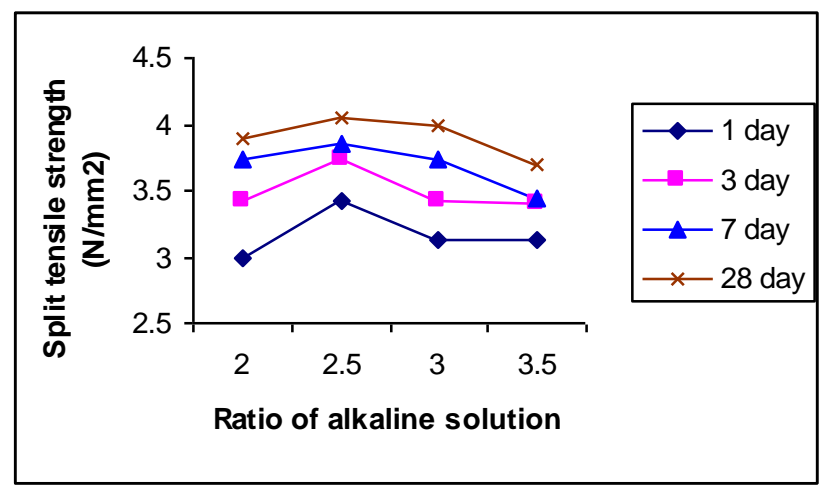

Fig. 11 Split tensile strength Vs Alkaline ratio (M-30)

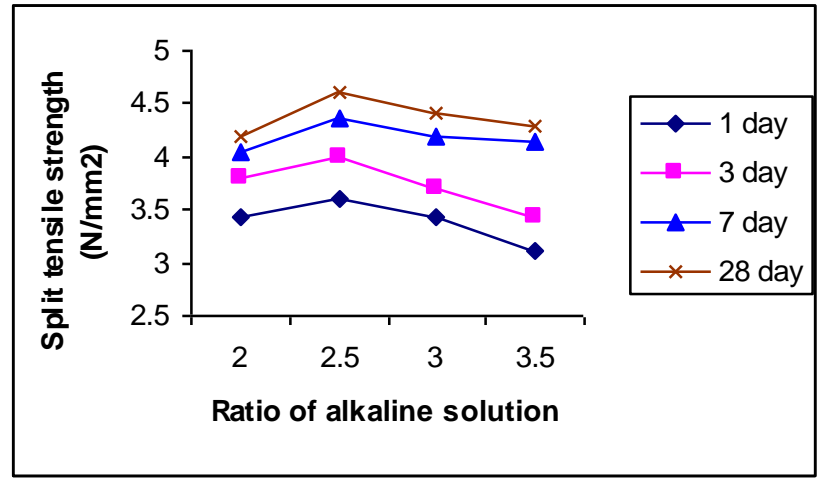

Fig. 12 Split tensile strength Vs Alkaline ratio (M-40)

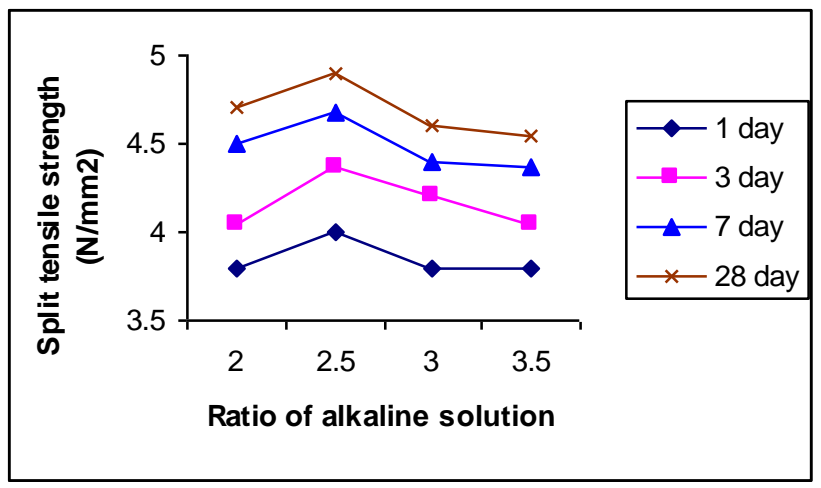

Fig. 13 Split tensile strength Vs Alkaline ratio (M-50)

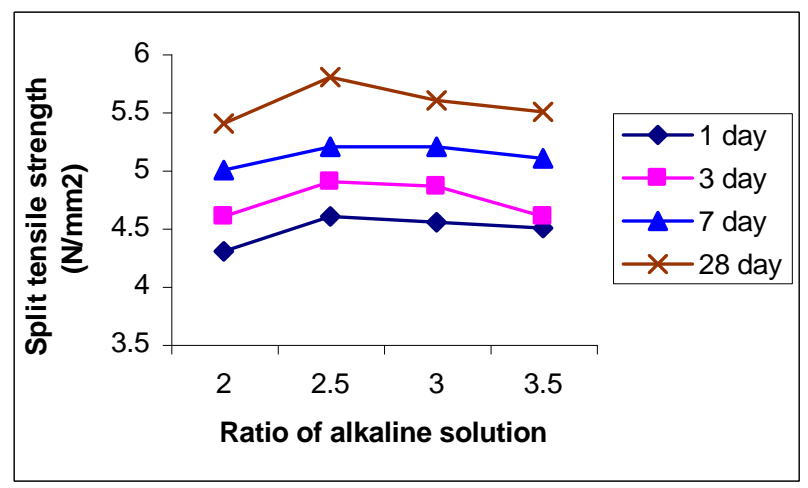

Fig. 14 Split tensile strength Vs Alkaline ratio (M-60) 